\title{
Successful closure of atrial septal defect by retrograde transarterial approach after unsuccessful transfemoral venous approach is
}

\author{
Sadık Volkan Emren ${ }^{\text {a,* }}$, Hamza Duygu ${ }^{\mathrm{b}}$, Asım Oktay Ergene ${ }^{\mathrm{c}}$, Rahman Bilal Gediz ${ }^{\mathrm{d}}$, Cem Nazli ${ }^{\mathrm{e}}$ \\ a Afyonkarahisar State Hospital Department of Cardiology Afyonkarahisar, Turkey \\ ${ }^{\mathrm{b}}$ Near East University Department of Cardiology Nicosia, Cyprus \\ c Dokuz Eylül University School of Medicine Department of Cardiology Izmir, Turkey \\ ${ }^{\mathrm{d}}$ Urla State Hospital Department of Cardiology Izmir, Turkey \\ e Katip Celebi University Atatürk Training and Research Hospital, Turkey
}

\section{A R T I C L E I N F O}

\section{Article history:}

Received 21 May 2016

Accepted 21 May 2016

Available online 26 May 2016

\section{Keywords:}

Atrial septal defect

Interventional cardiology

Congenital heart disease

\begin{abstract}
A B S T R A C T
Although many of the ostium secundum atrial septal defects can be successfully closed by percutaneous transvenous approach, surgical method as well is preferred in some cases due to vascular reasons or due to the anatomical characteristics of the defect. Detecting ostium secundum atrial septal defect in a 26-year-old female patient, who presented with shortness of breath, percutaneous closure procedure was planned. During percutaneous closure, it was observed that guidewire and catheter persistently went towards patent foramen ovale because of quite flaccid structure of interatrial septum. For this reason, occluder could not be placed in the defect area. Before using the option of surgery for the patient, guidewire and simmons 1 diagnostic catheter were pushed forward towards to the left ventricle and then left atrium by transarterial approach through the femoral artery. Guidewire and the catheter were easily passed through atrial septal defect without passing through patent foramen ovale benefiting from the left atrial pressure. Occluder was retrogradely carried via transarterial route and successfully implanted in the defect area. Transarterial approach may be an alternative before surgery in selected cases in which percutaneous closure of atrial septal defect has failed.

(C) 2016 The Society of Cardiovascular Academy. Production and hosting by Elsevier B.V. All rights reserved. This is an open access article under the CC BY-NC-ND license (http://creativecommons.org/licenses/by-nc-nd/4.0/)
\end{abstract}

\section{Introduction}

Atrial septal defect is one of the most prevalent congenital heart diseases in adulthood. ${ }^{1}$ The most common type of atrial septal defect is the ostium secundum atrial septal defect, which accounts for $75 \%$ of overall atrial septal defect cases. ${ }^{2}$ Today, secundum atrial septal defect is widely treated by a closure device implanted via percutaneous transvenous route. $^{3}$ Although closure device implantation is an effective and reliable procedure, there may be some procedure-related difficulties. One of the most important difficulties is the flaccid septal tissue encountered in case of co-existence of atrial septal defect and patent foramen ovale. In such cases, the catheter heads towards the loose tissue instead of the defect area during procedure and makes the implantation difficult.

Herein, we present an adult atrial septal defect case, which had undergone successful device implantation by transarterial approach after unsuccessful attempts via transvenous approach due to presence of patent foramen ovale and loose septal tissue.

\footnotetext{
th The authors report no financial relationships or conflicts of interest regarding the content herein.

* Corresponding author. Tel.: +90 5052644578; fax: +90272 2147575

E-mail addresses: vemren@hotmail.com (S.V. Emren), hamzakard@yahoo.com

(H. Duygu), oktayergene@yahoo.com (A.O. Ergene), bilalgediz@hotmail.com (R.B. Gediz).

Peer review under responsibility of The Society of Cardiovascular Academy.
}

Case

A 26-year-old female patient presented with effort dyspnea. Her personal medical history revealed no documented known cardiac disease. Her blood pressure was $115 / 70 \mathrm{~mm} \mathrm{Hg}$, pulse rate was $75 \mathrm{bpm}$ and rhythmic. Cardiac examination revealed a grade of $2 / 6$ systolic murmurs on pulmonary area. Electrocardiography was in sinus rhythm with incomplete right bundle branch block. Her laboratory parameters were within the normal limits. Transthoracic echocardiography showed dilated right ventricle, with mild tricuspid regurgitation and estimated systolic pulmonary pressure measured from Bernoulli equation was $35 \mathrm{~mm} \mathrm{Hg}$. Atrial shunt was detected with color Doppler from apical four-chamber view. Transesophageal echocardiography revealed a $19 \mathrm{~mm}$ defect in interatrial septum, compatible with ostium secundum atrial septal defect. Patent foramen ovale, which was $4 \mathrm{~mm}$ in diameter and $10 \mathrm{~mm}$ in length, was detected $11 \mathrm{~mm}$ distant from the atrial septal defect. Despite flaccid interatrial septum, rims of the defect were considered to be appropriate for percutaneous closure.

The procedure was performed under general anesthesia with transesophageal echocardiography. A 7-F sheath was placed through the right femoral vein. Afterwards, an attempt was made to pass into the left atrium with a 7-French multipurpose catheter over a $0.35 \mathrm{j}$-tipped wire. Despite many attempts, however the catheter persistently headed 
towards to patent foramen ovale instead of atrial septal defect because of flaccid interatrial septal tissue and entered into the left atrium through patent foramen ovale. Upon this, it was planned to pass the catheter through atrial septal defect from the opposite side, through the left atrium benefiting from the direction of shunt flow in the interatrial septum to prevent the wire passing through patent foramen ovale. For this purpose, a 7-French sheath was placed into the right femoral artery at first. Thereafter, Simmons 1 diagnostic catheter was passed through the aortic valve over $0.35 \mathrm{j}$-tipped long guidewire, and pushed into the left ventricle. Accordingly, the catheter was pushed forward over the wire and passed into the left atrium through the left ventricle. By further pushing forward the wire, right atrium was reached through the left side. The wire was passed through the right ventricle and the main pulmonary artery. The wire in the right pulmonary artery was caught with a snare, which was sent through the right femoral vein, and pulled out of the right femoral vein sheath. Thus, an arteriovenous loop had been created. The size of the defect was measured to be $19.4 \mathrm{~mm}$ by sizing balloon (Fig. 1). A $22 \mathrm{~mm}$ Cardio-O-Fix (Starway Medical Technology, Beijing, China) closure device was loaded in the delivery system and pushed forward into the left ventricle via aortic route and then passed through the left atrium to the right atrium. The left atrial disk of the device was opened in the right atrium, slightly pulled back, and then leant on the interatrial septum. Afterwards, the right atrial disk was allowed to open in the left atrium. Transesophageal echocardiography demonstrated that shunt flow had stopped.
Lock system of the device was opened and the device was left in the interatrial septum. Before finalizing the procedure, mitral valve function and caval and pulmonary flows were checked for procedure-related complications. Control transthoracic echocardiography was performed one day after procedure and the device was visualized in place, with no residual shunt flow (Fig. 2), and the patient was discharged from the hospital.

\section{Discussion}

To our knowledge, the present case is the first case, which had undergone atrial septal defect closure by retrograde approach, reported in the literature. Cases that had undergone atrial septal defect closure by non-femoral venous approach have been reported previously. In these cases, the main reason for preferring non-femoral venous approach is anatomical and mechanical inconvenience of the vascular system, through which the device would be pushed forward. The most striking reasons have been the presence of thrombus, interruption and total occlusion of the inferior vena cava. ${ }^{4-8}$ Most frequently, jugular vein had been preferred in those cases; but the device had been rarely implanted using transhepatic approach as well. In the present case, the basic difference was the absence of anatomical vascular problem. The main reason for not preferring jugular vein in the present case was the absence of anatomical problem in the inferior vena cava, which was the main reason also in the other cases, as well as the fact
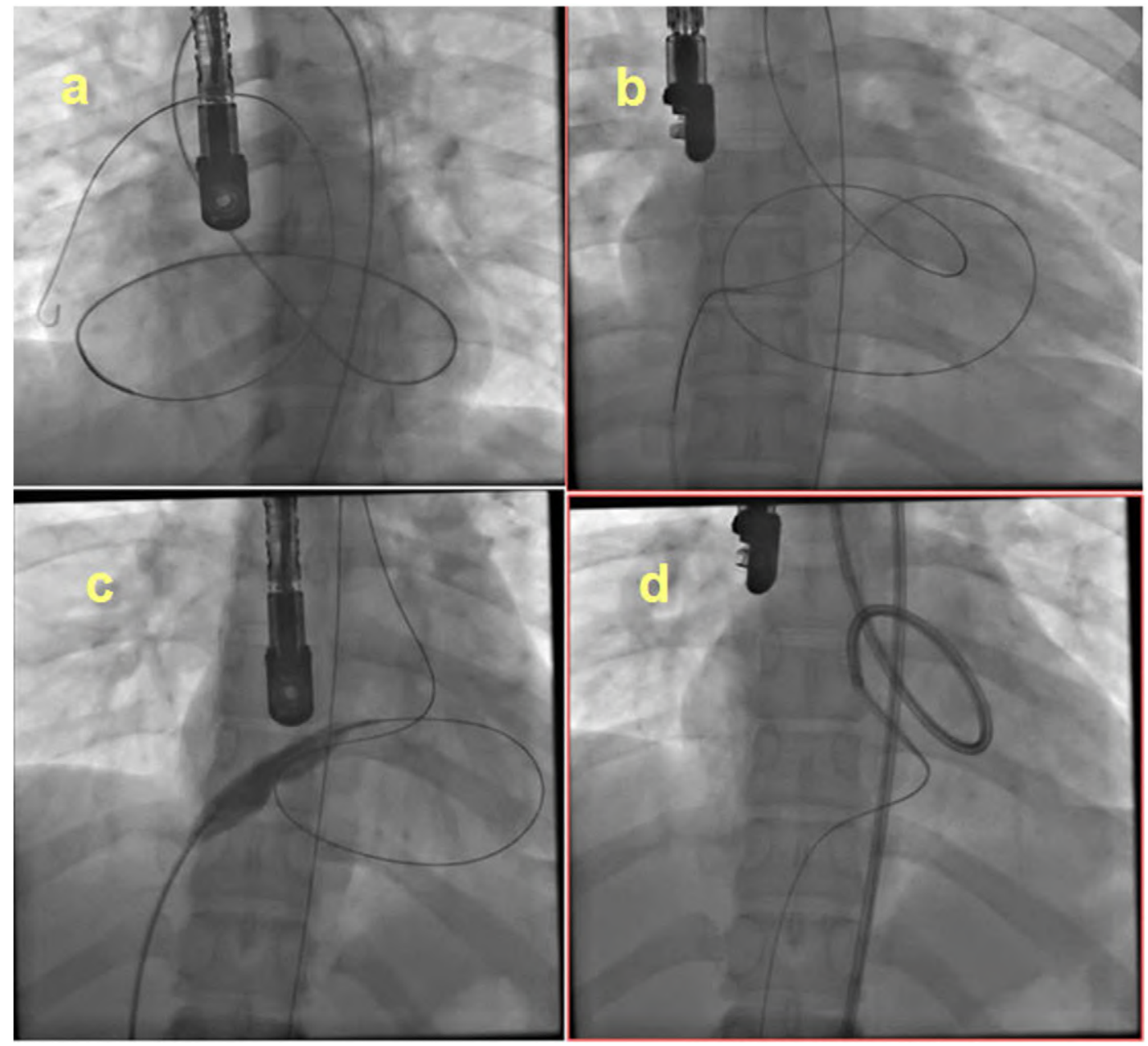

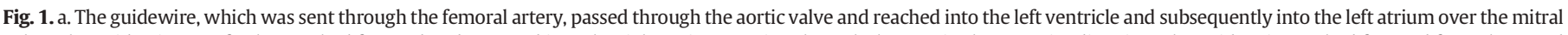

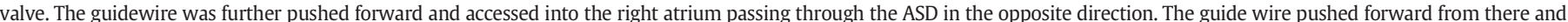

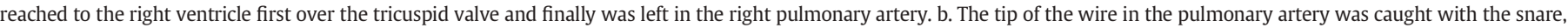

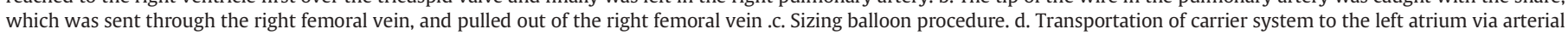
route and passage into the right atrium through ASD. 


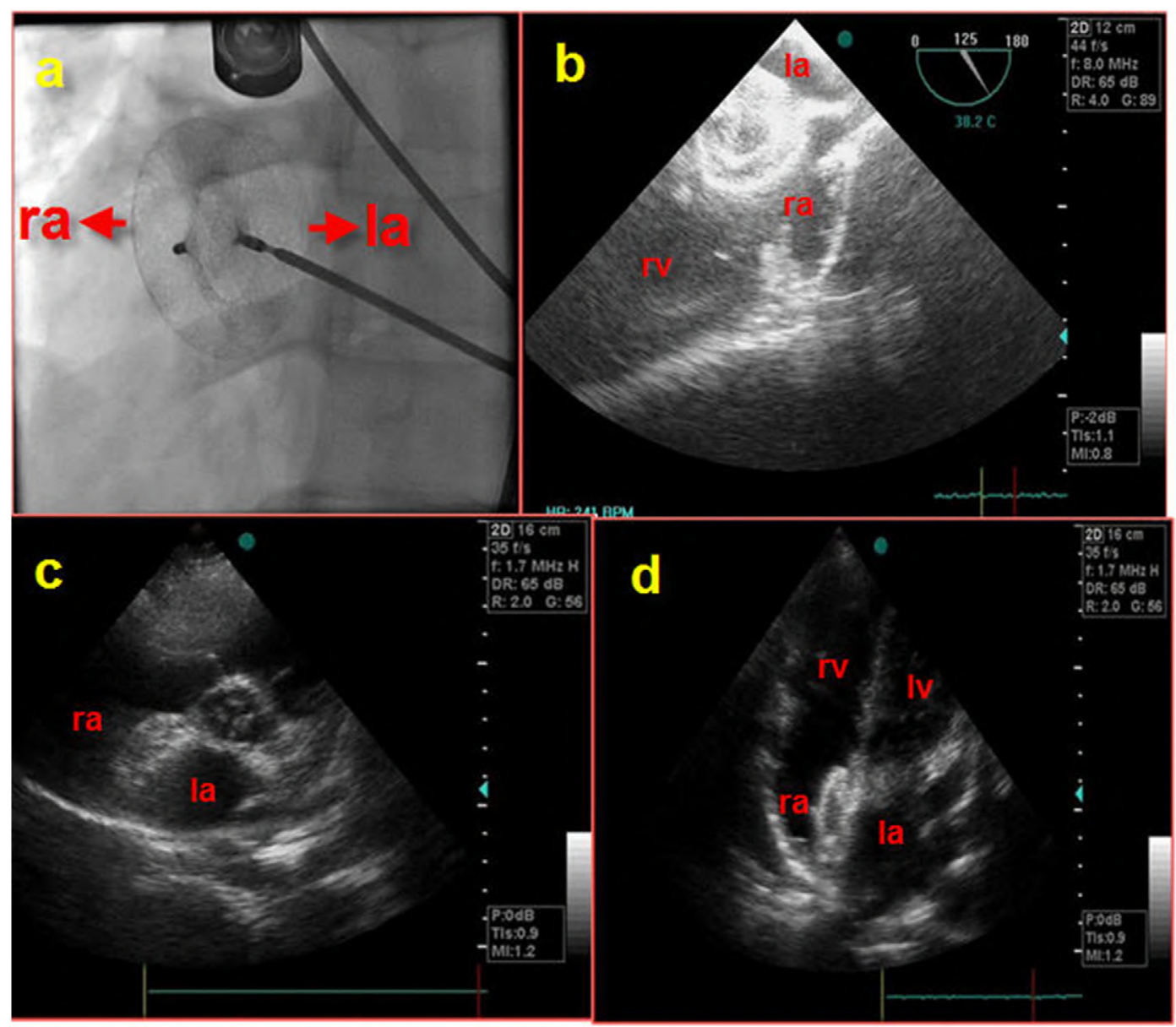

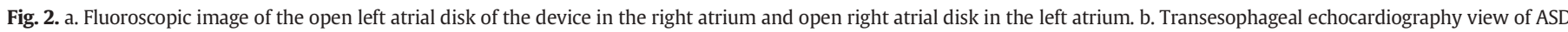
occluder. View of the device by short axis examination on post-procedure Day 1 . d. View of the device by apical four-chamber examination on post-procedure Day 1.

that passing the defect directly through atrial septal defect instead of patent foramen ovale and implantation of device so as to completely cover the interatrial septum would be more difficult via jugular venous route.

How to manage the cases with co-existing atrial septal defect and patent foramen ovale and with flaccid interatrial septum is unclear. According to the expert opinion, closure with a single patent foramen ovale device is one of the recommendations in the event the distance between atrial septal defect and patent foramen ovale is close.

The other recommendation is the closure of patent foramen ovale with a patent foramen ovale device and closure of atrial septal defect with another device in the same session. ${ }^{9}$ We didn't prefer this method for several reasons. First In the present case, it was thought that, a single patent foramen ovale device wouldn't be wide enough to close the atrial septal defect, as for there was distance in between patent foramen ovale and atrial septal defect. The second reason, it was difficult to pass separately through ASD closure device in case patent foramen ovale is closed with the patent foramen ovale closure device which could cause the probability of unsuccessfulness. And also implantation of two devices might cause the probability of increased risk of complications.

As known, the patent foramen ovale opens into the left atrium from the right atrium because of its anatomical configuration. The patent foramen ovale remains closed, no blood flows into the right atrium from the left due to higher left atrial pressure. Atrial septal defect instead of patent foramen ovale was easily passed by retrograde approach benefiting from the direction of shunt flow as well as from physiological and anatomical properties of patent foramen ovale, and the defect was successfully closed with a single device.

\section{Conclusion}

Although transfemoral atrial septal defect closure is currently the preferred choice of procedure, retrograde closure by transarterial approach can be preferred in selected cases, in which interatrial septum anatomy is not suitable for closure by transfemoral venous approach.

\section{References}

1. Lindsey JB, Hillis LD. Clinical update: atrial septal defect in adults. Lancet 2007;369: 1244-1246.

2. Fuster V, Brandenburg RO, McGoon DC, Giuliani ER. Clinical approachand management of congenital heart disease in the adolescent andadult. Cardiovasc Clin 1980;10: 161-197.

3. Warnes CA, Williams RG, Bashore TM, et al. ACC/AHA 2008 guidelines for the Management of Adults with congenital heart disease: a report of the American College of Cardiology/American Heart Association task force on practice guidelines (writing committee to develop guidelines on the Management of Adults with congenital heart disease). Circulation 2008:118:714-833.

4. Xu B, Zaman S, Harper R. Successful closure of a large secundum atrial septal defect via the transjugular approach after failed transfemoral Xu B., Zaman S., Harper R. Int J Cardiol 2015; 186:322-324.

5. Baspinar O, Al-Hadidy KI, Kervancioglu M. Transjugular closure of a two-hole atrial septal defect in a child with iliac vein thrombosis. Ann Pediatr Cardiol 2013;6: 185-187.

6. Emmel M, Sreeram N, Pillekamp F, et al Transhepatic approach for catheterinterventions in infants and children with congenital heart diseases. Clin Res Cardiol 2006;95:329-333.

7. Papa M, Gaspardone A, Fragasso G, et al. Jugular approach for percutaneous closure of atrial septal defect. Ital Heart J 2004;5:466-469.

8. Ozbarlas N, Kiziltas A, Kucukosmanoglu O, Erdem S. Transjugular approach to device closure of atrial septal defect in a child with heterotaxia and interrupted inferior vena cava. Tex Heart Inst J 2012;39:435-437.

9. Harper RW, Mottram MP, McGaw DJ. Closure of secundum atrial septal defects with the Amplatzer septal occluder device:techniques and problems. Catheter Cardiovasc Interv 2002;57:508-524. 